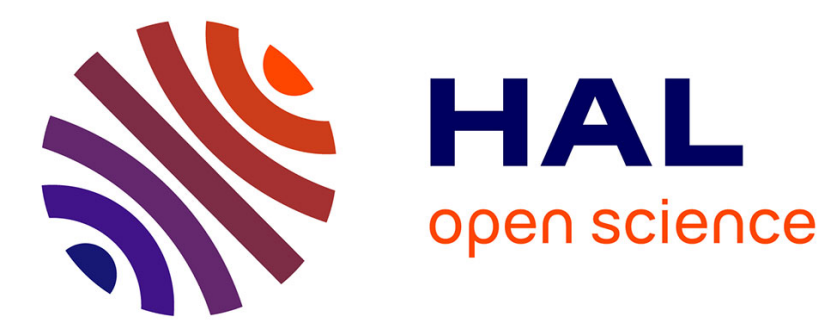

\title{
Crystalline magnesium nitride ( Mg3N2 ): From epitaxial growth to fundamental physical properties
}

P. John, H. Rotella, C. Deparis, G. Monge, Frédéric Georgi, P. Vennéguès, M. Leroux, J Zúñiga-Pérez

\section{- To cite this version:}

P. John, H. Rotella, C. Deparis, G. Monge, Frédéric Georgi, et al.. Crystalline magnesium nitride ( Mg3N2 ): From epitaxial growth to fundamental physical properties. Physical Review Materials, 2020, 4 (5), 10.1103/physrevmaterials.4.054601 . hal-03045516

\section{HAL Id: hal-03045516 https://hal.science/hal-03045516}

Submitted on 15 Dec 2020

HAL is a multi-disciplinary open access archive for the deposit and dissemination of scientific research documents, whether they are published or not. The documents may come from teaching and research institutions in France or abroad, or from public or private research centers.
L'archive ouverte pluridisciplinaire HAL, est destinée au dépôt et à la diffusion de documents scientifiques de niveau recherche, publiés ou non, émanant des établissements d'enseignement et de recherche français ou étrangers, des laboratoires publics ou privés. 


\title{
Crystalline magnesium nitride $\left(\mathrm{Mg}_{3} \mathrm{~N}_{2}\right)$ : from epitaxial growth to fundamental physical properties
}

\author{
P. John ${ }^{1}$, H. Rotella ${ }^{1}$, C. Deparis ${ }^{1}$, G. Monge ${ }^{2}$, F. Georgi ${ }^{2}$, P. Vennéguès ${ }^{1}$, M. Leroux ${ }^{1}$, and J. Zuniga- \\ Perez ${ }^{1, *}$ \\ ${ }^{1}$ CRHEA, CNRS, UCA, Rue Bernard Gregory, 06560 Valbonne, France \\ ${ }^{2}$ CEMEF-MINES ParisTech, 1 rue Claude Dannesse, 06904 Sophia Antipolis Cedex, France \\ *Corresponding author: jzp@crhea.cnrs.fr
}

\begin{abstract}
Single-crystalline $\mathrm{Mg}_{3} \mathrm{~N}_{2}$ thin films are grown on $\mathrm{MgO}(100)$ substrates by plasma-assisted molecular beam epitaxy. To prevent the oxidation of the $\mathrm{Mg}_{3} \mathrm{~N}_{2}$ films and allow further physical characterization, a polycrystalline $\mathrm{MgO}$ cap is deposited in-situ. The growth orientation of the $\mathrm{Mg}_{3} \mathrm{~N}_{2}$ films can be tuned from (100) to (111) by changing the growth conditions and the associated epitaxial relationships have been determined by means of X-ray diffraction. The lattice constant of $\mathrm{Mg}_{3} \mathrm{~N}_{2}$ films has been monitored as a function of temperature from $300 \mathrm{~K}$ to $900 \mathrm{~K}$, determining thereby the linear thermal expansion coefficient. Transmission measurements indicate an optical bandgap of crystalline $\mathrm{Mg}_{3} \mathrm{~N}_{2}$ around $2.9 \mathrm{eV}$ at room-temperature, consistent with diffuse reflectance measurements on micrometric $\mathrm{Mg}_{3} \mathrm{~N}_{2}$ particles. These results demonstrate the possibility of exploiting $M g_{3} N_{2}$ as a new crystalline semiconductor in the blue-violet range.
\end{abstract}




\section{INTRODUCTION}

The study of new semiconductors requires the synthesis of high-quality material to ensure that the measurement of fundamental physical properties such as lattice parameters, electron effective mass or bandgap is not perturbed by the presence of defects. A prototypical example is $\ln N$, whose bandgap was considered for many years to be about $1.9 \mathrm{eV}$ (see [1] and references therein). Once samples of high-enough quality became available in the early 2000s [2,3], its actual bandgap could be reliably measured to be about $0.7 \mathrm{eV}$.

Another nitride, $\mathrm{Mg}_{3} \mathrm{~N}_{2}$, lives today a similar situation. This is rather surprising given that its antibixbyite structure and its lattice parameters were measured on powder samples and $\mathrm{mm}$-long single crystals as soon as 1933 [4], being later refined in the nineties [5]. Ceramic $\mathrm{Mg}_{3} \mathrm{~N}_{2}$ has been used in industry for years as a nitriding agent for the formation of various nitrides [6, 7], and as a catalyst for the synthesis of superhard silicon nitride and cubic boron nitride [8]. More recently, it has found its own applications as high-thermal conductivity ceramics when doped with silicon [9] and as a reversible hydrogen storage material [10]. Interestingly, all these applications use magnesium nitride for its physicochemical properties while none exploits its optoelectronic ones.

The few theoretical calculations that exist on crystalline $\mathrm{Mg}_{3} \mathrm{~N}_{2}$ predict it to be a semiconductor with an energy gap between $1.1 \mathrm{eV}$ to $2.26 \mathrm{eV}$, depending on the actual calculation method [11,12,13]. Two of these works $[11,12]$ indicate a direct bandgap, while the third calculation [13] finds an energy difference of about $10 \mathrm{meV}$ between the indirect and direct transitions that would result, in practice, in a direct character semiconductor. However, these values are far from those evaluated experimentally, which range from a minimum measured value of $2.5 \mathrm{eV}$ obtained by transmission measurements [14], through $2.8 \mathrm{eV}-2.9 \mathrm{eV}$ as determined by reflectance and photoluminescence excitations measurements $[11,15]$, respectively, to a largest value of $3.15 \mathrm{eV}$ at room-temperature measured by reflectance measurements too [16]. Besides the basic interest on the fundamental properties of a new material, determining its electronic properties can also be relevant from a 
technological point of view. In the case of $\mathrm{Mg}_{3} \mathrm{~N}_{2}$ this applicative interest arises in the context of solar energy, since by alloying it with $\mathrm{Zn}_{3} \mathrm{~N}_{2}$ one can tune its absorption edge to an optimum of $1.4 \mathrm{eV}$ [17], and especially in the context of GaN-based optoelectronics. Indeed, $\mathrm{Mg}_{3} \mathrm{~N}_{2}$ has been detected in highlydoped GaN:Mg samples $[18,19,20]$ and has been shown to decrease the $p$-doping level. Given the widespread use of GaN optoelectronic devices, including light-emitting diodes and laser diodes, and the usage of $\mathrm{Mg}$ as its only efficient $p$-dopant, unravelling the basic electronic properties of $\mathrm{Mg}_{3} \mathrm{~N}_{2}$ is of major technological relevance.

In this article we discuss the epitaxial growth of $\mathrm{Mg}_{3} \mathrm{~N}_{2}$ thin films by molecular beam epitaxy (MBE) and we analyze their structural properties by X-ray reflectivity (XRR) and high-resolution X-ray diffraction (HRXRD), paying special attention in demonstrating their epitaxial character. Before studying the films physical properties, the in-situ deposition of a protective MgO layer will be examined as a means of preventing the otherwise irreversible decomposition of the $\mathrm{Mg}_{3} \mathrm{~N}_{2}$ films when exposed to air. Subsequently, the structural quality of the films and the evolution of lattice parameter with temperature will be evaluated. Finally, the optical bandgap of such epitaxial films will be measured and compared to that of commercially-available $\mathrm{Mg}_{3} \mathrm{~N}_{2}$ microparticles.

\section{EXPERIMENTAL METHODS}

Epitaxial $\mathrm{Mg}_{3} \mathrm{~N}_{2}$ thin films, with thicknesses typically in the $100 \mathrm{~nm}$ range, were grown by plasmaassisted MBE on commercial MgO(100) substrates purchased from CRYSTAL. The substrates were prepared by rapid thermal annealing for 2 minutes at $1150{ }^{\circ} \mathrm{C}$ under oxygen atmosphere in order to achieve an atomically-flat step-and-terrace morphology. Growth was then performed in a Riber EPINEAT II-VI system equipped with an effusion cell for elemental Mg $(6 \mathrm{~N})$. High purity nitrogen and oxygen gases $(6 \mathrm{~N})$ were introduced through radio-frequency plasma cells operated at a power of $360 \mathrm{~W}$ and $400 \mathrm{~W}$, respectively. The substrate temperature was measured with a pyrometer directed 
onto the sample. In-situ optical reflectivity and reflection high-energy electron diffraction (RHEED) were used to monitor the growth rate and characterize the surface crystallinity.

The surface morphology of the MgO capping films was measured by atomic force microscopy (AFM) using a Bruker Edge system, while the structural properties of the $\mathrm{Mg}_{3} \mathrm{~N}_{2}$ films were evaluated by HRXRD and XRR using a Panalytical X'Pert Pro MRD system using $C u K_{\alpha 1}$ radiation. The temperaturedependent XRD measurements were performed in an Empyrean Panalytical using both $\mathrm{Cu} \mathrm{K}_{\alpha 1}$ and $\mathrm{K}_{\alpha 2}$ lines and a polycapillary as incident optics. The samples were kept in a closed chamber (Anton Paar) and nitrogen was flown through continuously during the measurements and the temperature ramps. X-ray photoelectron spectroscopy (XPS) has been used to qualify the films composition. The measurements have been carried out in a Thermo Scientific system equipped with an Al $\mathrm{K}_{\alpha}$ monochromated source, a low energy flood-gun for charge compensation and an $\mathrm{Ar}^{+}$ion gun for depth profiling. Finally, white-light transmission and reflectance measurements were employed to measure the absorption coefficient and diffuse scattering, respectively.

\section{REACTIVITY OF $\mathrm{Mg}_{3} \mathrm{~N}_{2}$ UPON AIR EXPOSURE: MgO CAPPING LAYER}

$\mathrm{Mg}_{3} \mathrm{~N}_{2}$ is known to decompose under ambient conditions, reacting in particular with water. This process leads to the formation of oxides, oxynitrides and, mostly, magnesium hydroxides $[21,22,23]$. To quantify the speed at which decomposition occurs we purchased commercial $\mathrm{Mg}_{3} \mathrm{~N}_{2}$ powder from Alfa Aesar (99.5\% purity) with a nominal particle size of $44 \mu \mathrm{m}$, which was confirmed by scanning electron microscopy measurements revealing particle sizes in the same scale.

Figure 1 presents the XRD patterns of the $\mathrm{Mg}_{3} \mathrm{~N}_{2}$ powder kept under ambient conditions as a function of time. Initially the powder is yellowish in colour, while after reaction in air it becomes completely white and increases drastically in volume. It appears after one hour of exposure to air that the powder begins to decompose. Although no XRD signal from $\mathrm{Mg}(\mathrm{OH})_{2}$ is yet visible, the intensity of the $\mathrm{Mg}_{3} \mathrm{~N}_{2}$ peaks decreases already. Indeed, initially only the surface of the micrometric particles is decomposed, and only when the reaction spreads into the volume a signal is detected from the magnesium 
hydroxide phase, which ends up dominating the XRD pattern after 24 hours. To assess quantitatively the decomposition kinetics of the $\mathrm{Mg}_{3} \mathrm{~N}_{2}$ powder we evaluated the peak areas of the four reflections shown in Figure 1 as a function of time. Using an exponential fit for the peak areas we obtain a mean time constant, averaged over all four reflections, of $\tau_{\text {decompostion }}=5.5 \pm 0.2 \mathrm{~h}$ in ambient conditions.

Since the thin films grown in this study, with thicknesses in the $100 \mathrm{~nm}$ range, display a larger surfaceto-volume ratio than the microparticles discussed above ( $44 \mu \mathrm{m}$ in diameter), their decomposition rate can be expected to be even larger than that of the powder. Thus, it is absolutely necessary to develop a capping layer that can be deposited in the MBE reactor prior to the removal of the $\mathrm{Mg}_{3} \mathrm{~N}_{2}$ films and their exposure to air.

Due to its high chemical stability and ionic Mg-O bond nature (cohesive energy of $10.33 \mathrm{eV}$ [24]), MgO seems a suitable candidate, though counterintuitive due to the presence of oxygen in the compound. If we assume, as will be confirmed in the following, that the oxygen from the $\mathrm{MgO}$ cap does not react with the underlying $\mathrm{Mg}_{3} \mathrm{~N}_{2}$, one still needs to insure that the quality of the capping, in particular its compactness, is sufficient to prevent contact between the film and the ambient moisture. Thus, the optimization parameter for the $\mathrm{MgO}$ cap has been chosen to be the surface roughness. $\mathrm{MgO}$ thin films were grown homoepitaxially in the same $\mathrm{MBE}$ reactor on $\mathrm{MgO}(100)$ substrates. Prior to growth, the substrates were annealed ex-situ at high temperature $\left(\sim 1150^{\circ} \mathrm{C}\right)$ so as to remove any polishing residue/scratch from their surface and promote the formation of atomically-flat terraces, as illustrated by the AFM image (see Figure 2). A complete series of samples was analyzed by AFM: Figure 2 displays the roughness evolution as a function of growth temperature and oxygen flow, the $z$ scale providing the root mean square roughness extracted from the analysis of $2 \times 2 \mu \mathrm{m}^{2}$ images.

At low substrate temperature and oxygen flow, Figure 2(a), the surface exhibits cubic grains with a height and width of about $100 \mathrm{~nm}$ but displays an incomplete wetting of the substrate, which is unacceptable for the current use. An increase of oxygen flow at intermediate temperatures slows down (eventually prevents) $\mathrm{MgO}$ growth, with nucleation taking place randomly on the substrate and leading to isolated agglomerates (Figure 2(b)). At the highest substrate temperature $\left(\sim 650^{\circ} \mathrm{C}\right.$ ) and 
large oxygen flow $(0.40 \mathrm{sccm}$, Figure 2(c)), nucleation occurs along the atomic steps present on the annealed substrate. The $\mathrm{MgO}$ crystallites have a cubic shape with a $40 \mathrm{~nm}$ base. Finally, at temperatures around $580^{\circ} \mathrm{C}$ and oxygen flows around $0.35 \mathrm{sccm}$, Figure $2(\mathrm{~d})$, the substrate surface is completely wetted and the roughness $(1.4 \mathrm{~nm})$ is the lowest of the series. For these optimized conditions, the $\mathrm{MgO}$ film consists of square grains with lateral sizes of $40 \mathrm{~nm}$ and heights, above the mean surface, between 1 and $5 \mathrm{~nm}$. Under these growth conditions an $\mathrm{MgO}$ growth rate of $63 \mathrm{~nm} / \mathrm{h}$ has been measured by XRR on a $\mathrm{MgO} / \mathrm{CdO}$ multilayer structure. In the following, all the $\mathrm{Mg}_{3} \mathrm{~N}_{2}$ films were covered with a nominally $50 \mathrm{~nm}$ thick MgO cap grown under the optimized conditions.

\section{IV. $\mathrm{Mg}_{3} \mathrm{~N}_{2}$ EPITAXIAL GROWTH: CRYSTAL ORIENTATION TUNABILITY}

Figure 3 illustrates the effect of $\mathrm{Mg} / \mathrm{N}$ ratio and temperature on the growth orientation of $\sim 100 \mathrm{~nm}$ thick $\mathrm{Mg}_{3} \mathrm{~N}_{2}$ thin films grown on $\mathrm{MgO}(100)$ substrates. Note that the XRD patterns were recorded with a fully opened detector to detect any possible contribution from parasitic phases. At $400{ }^{\circ} \mathrm{C}$ and the smallest $\mathrm{Mg} / \mathrm{N}$ ratio the growth direction is unique and parallel to [100], consistent with a recent study reporting first attempts to grow single-crystal $\mathrm{Mg}_{3} \mathrm{~N}_{2}$ films [14]. Note that a shoulder on the lower side of the MgO substrate (200) peak, which might be attributed to MgON formed at the substrate/layer interface, appears under these growth conditions. Furthermore, the associated RHEED pattern (Inset (A) in Figure 3(a)) is streaky for the first $20 \mathrm{~nm}$, but becomes spotty afterwards, the spots being elongated along circular arcs as the growth proceeds. Under these growth conditions, the thicker the thin film the worse the structural quality, as attested by the increase of the circular arcs length (indicating an increase of the relative twist of the grains). The in-plane lattice parameter of $\mathrm{Mg}_{3} \mathrm{~N}_{2}$ (200) was determined from the RHEED pattern to be $4.65 \pm 0.24 \AA$, indicating a strong compressive in-plane strain with respect to the relaxed lattice (literature value of $4.976 \AA$ ) at the beginning of the growth. As the nitrogen flow is diminished, the (100) orientation is maintained while the parasitic MgON phase disappears completely. A further reduction of the nitrogen flow leads to the appearance of grains oriented parallel to [111], giving rise to polycrystalline thin films displaying concomitantly (111) and 
(100) grains. Interestingly, a further reduction of the nitrogen flow and/or increase of the $\mathrm{Mg}$ cell temperature (i.e. an increase of the $\mathrm{Mg} / \mathrm{N}$ ratio) results in $\mathrm{Mg}_{3} \mathrm{~N}_{2}$ thin films displaying again one single orientation, but this time (111). The RHEED pattern, which is still spotty (Inset (E) in Figure 3(a)), can be modeled with diffraction from three families of crystallographic planes, as represented by the coloured dots in Inset (E). The exact epitaxial relationships giving rise to such a diffraction pattern will be discussed in Section V. If under these last growth conditions we increase the growth temperature, we recover a streaky RHEED pattern corresponding to a flat (111) surface (Inset (F) in Figure 3(a)). It is thus possible to tune the growth orientation of $\mathrm{Mg}_{3} \mathrm{~N}_{2}$ on $\mathrm{MgO}(100)$ from (100) to (111) by switching from $\mathrm{N}$-rich to more Mg-rich growth conditions.

As shown in Figure 3(b), where the growth rate of $\mathrm{Mg}_{3} \mathrm{~N}_{2}$ films is plotted as a function of the $\mathrm{Mg}$ cell temperature for a nitrogen flow of $0.35 \mathrm{sccm}$, the increase of $\mathrm{Mg}$ flux results also in an acceleration of the growth rate. This is an important aspect to keep in mind given that, similarly to other nitrides grown by plasma-assisted MBE (e.g. GaN or AIN), the actual growth rates are rather low (typically in the order of $2 \mathrm{~nm} / \mathrm{min}$ for optimized growth conditions). Indeed, the maximum growth rates we have achieved are in the order of $2.6 \mathrm{~nm} / \mathrm{min}$ (equivalently, $312 \mathrm{~nm} / \mathrm{h}$ ), not shown here, but this requires either low temperatures and/or large $\mathrm{N}$ flow and $\mathrm{Mg}$ flux, far from the optimum growth conditions to achieve high-quality thin films. The increase of the growth rate up to a Mg cell temperature of $420^{\circ} \mathrm{C}$ to $430{ }^{\circ} \mathrm{C}$ (see Figure 2(b)) indicates a growth regime limited by $\mathrm{Mg}$ incorporation (i.e. N-rich). On the other hand, the saturation of the growth rate at a $\mathrm{Mg}$ cell temperature larger than $420^{\circ} \mathrm{C}$ to $430{ }^{\circ} \mathrm{C}$ indicates an excess of $\mathrm{Mg}$, i.e. Mg-rich conditions. The detailed growth conditions of samples $\mathrm{A}$ to $\mathrm{G}$ are displayed in Table I.

Before demonstrating the epitaxial character of the grown films and assessing some of their physical properties, let us discuss the role of the MgO cap. XPS measurements (not shown) enable to monitor the 1:1 (Mg:O) stoichiometry of the $\mathrm{MgO}$ cap as well as the presence of the underlying $\mathrm{Mg}_{3} \mathrm{~N}_{2}$ thin film, which is measured thanks to in-situ etching. However, the presence of oxygen in the capping layer prevents any quantitative analysis of the $\mathrm{Mg}_{3} \mathrm{~N}_{2}$ stoichiometry. The reason is that this cap must be 
eroded in-situ in the XPS chamber and, thus, a non-negligible background oxygen partial pressure is always present in the chamber when analyzing the underlying $\mathrm{Mg}_{3} \mathrm{~N}_{2}$ film and can oxidize it. This effect can be readily monitored in time, the oxygen concentration detected when eroding the $\mathrm{Mg}_{3} \mathrm{~N}_{2}$ slowly increasing as a function of the time passed between the erosion of the $\mathrm{MgO}$ and the measurement. To assess the abruptness of the $\mathrm{MgO}$ (cap)/ $\mathrm{Mg}_{3} \mathrm{~N}_{2}($ film) interface we have systematically employed XRR. Figure 4 shows a typical $\mathrm{X}$-ray reflectivity curve, measured on sample $\mathrm{F}$ from the series discussed above, displaying neat interference fringes. The fitting of the curve using the GenX software [25] indicates a total $\mathrm{MgO}$ cap thickness of $42 \mathrm{~nm}$ and a total $\mathrm{Mg}_{3} \mathrm{~N}_{2}$ thickness of $98 \mathrm{~nm}$. Most importantly, there is no indication of any interfacial layer between the two films and the $\mathrm{Mg}_{3} \mathrm{~N}_{2}$ roughness is in the order of $1 \mathrm{~nm}$, consistent with the observation of a streaky RHEED pattern measured at the end of the $\mathrm{Mg}_{3} \mathrm{~N}_{2}$ growth. In contrast, a roughness of $2.2 \mathrm{~nm}$ was extracted from the XRR of sample $\mathrm{E}$ (not shown here), being consistent with the observation of a spotty RHEED pattern. Note that the damping of the interference fringes at large $2 \theta$ angles for sample $\mathrm{F}$ in Figure 4 (displaying a streaky pattern) is caused by the $\mathrm{MgO}$ capping layer that displays a roughness of $5 \mathrm{~nm}$. Note also that the $\mathrm{Mg}_{3} \mathrm{~N}_{2}$ density extracted from the fitting, $2.56 \mathrm{~g} \mathrm{~cm}^{-3}$, is about $5 \%$ smaller than the tabulated density of $\mathrm{Mg}_{3} \mathrm{~N}_{2}$. While such discrepancies are often encountered in XRR measurements, they might also indicate a large vacancy density or the existence of grain boundaries.

\section{V. $\mathrm{Mg}_{3} \mathrm{~N}_{2}$ EPITAXIAL GROWTH: STRUCTURAL QUALITY AND EPITAXIAL RELATIONSHIPS}

As highlighted in the introduction, our main objective was to develop high-quality $\mathrm{Mg}_{3} \mathrm{~N}_{2}$ films to be able to assess their physical properties. One previous attempt in 2018 to grow such films by MBE (reference [14]) indicated that for films thinner than $800 \mathrm{~nm}$ the diffraction intensity was "barely detectable". According to the authors of this study, the reason was the presence of only light elements ( $\mathrm{Mg}$ and $\mathrm{N}$ ) in the film, leading to an overall diffracted intensity five orders of magnitude smaller than that of the MgO substrate (which, incidentally, consists also of light elements). 
Figure 5(a) shows the XRD $2 \theta / \omega$ scan of sample $F$ using a $1 / 4^{\circ}$ slit in the diffraction path. Besides confirming that no parasitic phases or orientations apart from the (111) are detected, it is noteworthy that a $100 \mathrm{~nm}$ thick $\mathrm{Mg}_{3} \mathrm{~N}_{2}$ film results in a diffracted intensity that is "just" three to four orders of magnitude smaller in intensity than that of the $\mathrm{MgO}(100)$ substrate, and well above the background level. This clearly indicates that $\mathrm{Mg}_{3} \mathrm{~N}_{2}$ films, even thin ones, can provide strong $\mathrm{X}$-ray diffraction, as soon as their crystalline quality is sufficiently high. To further illustrate the quality of the current $\mathrm{Mg}_{3} \mathrm{~N}_{2}$ films and compare them with other standard semiconductors, Figure $5(\mathrm{~b})$ shows the $2 \theta / \omega$ scan around the $\mathrm{Mg}_{3} \mathrm{~N}_{2}$ (222) reflection from the same sample recorded with a crystal analyzer (i.e. in triple axis configuration). The additional intensity peaks surrounding the main one arise due to finite-size effects along the growth direction and indicate a large degree of coherence along the longitudinal direction. This finite-size effect can be used to estimate very precisely the average film thickness. To do so we have simulated the X-ray diffraction pattern (red curve in Figure $5(b)$ ) considering a perfect crystal along the growth direction (i.e. perfect X-ray coherence) and no surface roughness. Under these assumptions the diffractogram is given by [26]

$$
I(\theta)=L(\theta)+F_{h k l}^{2} \cdot \frac{\sin ^{2}(2 \pi n h k l \sin (\theta / \lambda))}{\sin ^{2}\left(2 \pi d_{h k l} \sin (\theta / \lambda)\right)}
$$

where $L(\theta)$ is a Lorentzian function representing the diffuse scattering term, $F_{h k l}$ is the structure factor associated to the $(h k l)$ reflection, $n$ the number of unit cells along the $[h k l]$ direction, $d_{h k l}$ the interreticular distance between $(h k l)$ planes, and $\lambda$ the employed X-ray wavelength $(1.54056 \AA$, in our case). The best fit to our pattern gives an average out-of-plane lattice parameter of $2.869 \pm 0.001 \AA$ (literature value for fully-relaxed: $2.873 \AA$ A) and a total thickness of $339 \pm 1$ unit cells. The corresponding thickness is $97.3 \mathrm{~nm}$, which perfectly matches the thickness determined by XRR presented in the previous section. Note that our simulation does not reproduce the asymmetry between the low-angle and high-angle sides of the (222) peak, given that we have considered a homogenous strain state along the growth direction. This asymmetry reveals in fact the existence of an in-plane strain (and/or compositional) gradient that relaxes along the growth direction [26,27], the $\mathrm{Mg}_{3} \mathrm{~N}_{2}$ films being under more compressive in-plane strain closer to the substrate. This is consistent with the slight 
misalignment between the simulated RHEED patterns (calculated with fully-relaxed lattice parameters) and the experimental ones, shown in Inset (E) of Figure 3(a). The measured spacings between reciprocal lattice points indicate an in-plane (220) interplanar distance of $3.46 \pm 0.31 \AA$ (literature: $3.519 \AA$ ) and an out-of-plane (222) interplanar distance of 2.94 $\pm 0.37 \AA$ (literature: $2.873 \AA$ ). Thus, both XRD 2 $\theta / \omega$ scans an RHEED patterns confirm the in-plane compressive strain close to the film/substrate interface.

To assess the epitaxial character of the current films their in-plane orientation with respect to the $\mathrm{MgO}(100)$ substrate has been determined by measuring $\phi$-scans on asymmetrical reflections, the azimuth $\phi$ being defined as the angle by which the sample is rotated around an axis perpendicular to its surface. The results are presented in Figure 6. In principle, the out-of-plane crystallographic direction being [111], only three peaks are expected in the $\phi$-scan for the set of $\{440\}$ planes. Instead, we find experimentally twelve peaks (Figure 6(a)). In order to account for this fact we must restore to the theory of epitaxial domains formation developed by Grundmann et al. [28,29]: it indicates that due to the rotational mismatch between the three-fold symmetric film and the four-fold symmetric substrate (Figure 6(b)), four crystalline epitaxial domains are to be expected, leading to twelve peaks in the XRD $\phi$-scan. The in-plane orientations of the four epitaxial domains are schematically represented in Figure 6(c). Thus, the epitaxial relationships of our $\mathrm{Mg}_{3} \mathrm{~N}_{2}(111) / \mathrm{MgO}(100)$ films are given by

$$
\begin{aligned}
& {[1 \overline{1} 0] \mathrm{Mg}_{3} \mathrm{~N}_{2} \|[011] \mathrm{MgO}} \\
& {[11 \overline{2}] \mathrm{Mg}_{3} \mathrm{~N}_{2} \|[01 \overline{1}] \mathrm{MgO}}
\end{aligned}
$$

plus the three additional rotational domains obtained by rotating the $\mathrm{Mg}_{3} \mathrm{~N}_{2}$ structure by $90^{\circ}, 180^{\circ}$ and $270^{\circ}$ around the $\mathrm{Mg}_{3} \mathrm{~N}_{2}[111]$ direction normal to the surface. This result is in agreement with the RHEED pattern given in Inset (E) of Figure 3(a). Its simulation was performed using the epitaxial relations given above and the colours of the points correspond to the different epitaxial domains illustrated in Figure 6(c): The red dots represent the simulated diffraction pattern of $\{1 \overline{1} 0\}$ planes of the domain indicated in red, the yellow dots arise from the $\{1 \overline{1} 0\}$ planes of the domain indicated in 
yellow and the blue dots correspond to the diffraction of $\{11 \overline{2}\}$ planes of the domains indicated in blue and black in Figure 6(c).

The knowledge of the epitaxial relationships allows us also to develop an atomic model of the $\mathrm{Mg}_{3} \mathrm{~N}_{2}(111) / \mathrm{MgO}(100)$ interface, as displayed in Figure 6(d). In this atomic configuration the lattice mismatches between $\mathrm{Mg}_{3} \mathrm{~N}_{2}$ and $\mathrm{MgO}$ (2.3\% along $\mathrm{Mg}_{3} \mathrm{~N}_{2}[11 \overline{2}]$ and $18.2 \%$ along $\mathrm{Mg}_{3} \mathrm{~N}_{2}[1 \overline{1} 0]$, calculated with a domain phase matching condition of two $\mathrm{MgO}$ unit cells for one $\mathrm{Mg}_{3} \mathrm{~N}_{2}$ cell) do indicate a strong compressive strain on the $\mathrm{Mg}_{3} \mathrm{~N}_{2}$ films, consistent with the asymmetry discussed in Figure $5(b)$. Note finally that, as suggested by the above-mentioned theory, if rotational domains were to be eliminated while keeping the same crystal orientation, a means of rotational symmetry-breaking should be employed, e.g. by using voluntarily misoriented (100) substrates. Alternatively, other substrate orientations (e.g. $\mathrm{MgO}(111))$ could be used.

\section{LINEAR THERMAL EXPANSION COEFFICIENTS OF EPITAXIAL $\mathrm{Mg}_{3} \mathrm{~N}_{2}$}

Since for most materials epitaxy is carried out at temperatures greater than room temperature, the knowledge of their linear thermal expansion coefficient is essential in order to quantitatively analyze the lattice mismatch between thin film and substrate at the actual growth temperature. This, in turn, can enable the design of heterostructures sustaining pseudomorphic growth or, on the contrary, maximizing the initial strain of the film in order to favor rapid plastic relaxation. Besides, the thermal expansion coefficient influences numerous basic physical properties whenever temperature variations come into play; in particular, it can play an essential role in determining the temperature-dependence of the material bandgap [30].

To assess the linear thermal expansion coefficient $\alpha_{\mathrm{T}}\left[31\right.$ ] of the $\mathrm{Mg}_{3} \mathrm{~N}_{2}$ epitaxial films, as well as of the $\mathrm{MgO}$ substrate, we have measured the out-of-plane lattice parameters (see Figure $7(\mathrm{a})$ for the $\mathrm{Mg}_{3} \mathrm{~N}_{2}$ thin films) as a function of temperature in the temperature range from $300 \mathrm{~K}$ up to $1100 \mathrm{~K}$. In order to minimize systematic errors, we have employed the methodology introduced by Liu and Zheng to measure precisely the thermal expansion coefficient of silicon [32,33]. Figure $7(b)$ shows the variation 
of the $\mathrm{Mg}_{3} \mathrm{~N}_{2}$ (111) and $\mathrm{MgO}(100)$ interplanar distances as a function of temperature. For temperatures above $900 \mathrm{~K}$ no data points for $\mathrm{Mg}_{3} \mathrm{~N}_{2}$ are given, as its diffraction intensity decreases enormously. This points towards a pure thermal stability issue, given that all measurements were carried out under nitrogen atmosphere and no sign of oxidation could be detected in the XRD patterns. From the interplanar distances curves the expansion of both $\mathrm{Mg}_{3} \mathrm{~N}_{2}$ and $\mathrm{MgO}$ is seen to be linear in the current temperature range. The averaged linear thermal expansion coefficients obtained from a linear fit to all available data are $1.14 \pm 0.03 \times 10^{-5} \mathrm{~K}^{-1}$ and $1.30 \pm 0.02 \times 10^{-5} \mathrm{~K}^{-1}$ for $\mathrm{Mg}_{3} \mathrm{~N}_{2}$ and $\mathrm{MgO}$, respectively, and their applicability range corresponds to $300-900 \mathrm{~K}$ and $300-1100 \mathrm{~K}$, respectively. As displayed in Figures $8(a)$ and (b), a linear thermal expansion coefficient has been extracted point by point using

$$
\alpha_{T}=\frac{d_{\text {perp }}(T+\Delta T)-d_{\text {perp }}(T)}{\frac{1}{2} \cdot\left(d_{\text {perp }}(T+\Delta T)+d_{\text {perp }}(T)\right) \cdot \Delta T}
$$

where $d_{\text {perp }}$ corresponds to the out-of-plane lattice parameter, $T$ is the temperature and $\Delta T$ corresponds to the temperature difference between consecutive points.

The thermal expansion of $\mathrm{MgO}$ has been thoroughly studied previously given its common use as refractory material (see 34 and 35, and references therein). Our determination is consistent with the linear thermal expansion coefficients published in the 300-1200 K range (Figure 8(a)), which fall within the $1.05-1.53 \times 10^{-5} \mathrm{~K}^{-1}$ window. On the other hand, to our knowledge there is just one previous report on the thermal expansion coefficient of $\mathrm{Mg}_{3} \mathrm{~N}_{2}$ powder [36], which was conducted only in the lowtemperature range (from $10 \mathrm{~K}$ to $300 \mathrm{~K}$ ). Our data are thus complementary, as they extend the knowledge of the $\mathrm{Mg}_{3} \mathrm{~N}_{2}$ thermal expansion coefficient to higher temperatures. By combining both sets of data (Figure 8(b)) we can reproduce the well-known behavior of the thermal expansion coefficient as a function of temperature of numerous semiconductors. This prototypical form, with a fast increase of the thermal expansion coefficient at low temperatures and its saturation at high enough temperatures, can be explained by the selective excitation of acoustic and optical phonons $[37,38,39]$. Finally, it should be noted that our measurements indicate that $\mathrm{Mg}_{3} \mathrm{~N}_{2}$ has a thermal expansion coefficient that is comparable to that of cubic BN [40], and roughly two to three times larger than that of AIN [39] and GaN [41]. 


\section{BANDGAP OF EPITAXIAL $\mathrm{Mg}_{3} \mathrm{~N}_{2}$}

To measure the optical bandgap of epitaxial $\mathrm{Mg}_{3} \mathrm{~N}_{2}$ films and determine its temperature dependence, transmission measurements were carried out from low $(\sim 10 \mathrm{~K})$ to room-temperature and the absorption coefficient $(\alpha)$ was extracted therefrom. Besides, to be able to compare with previous measurements carried out on $\mathrm{Mg}_{3} \mathrm{~N}_{2}$ powder samples, we also measured diffuse reflectance as a function of temperature on the same micrometric $\mathrm{Mg}_{3} \mathrm{~N}_{2}$ particles that we have employed in Section III to analyze the chemical reactivity of $\mathrm{Mg}_{3} \mathrm{~N}_{2}$ in ambient conditions.

As shown in Figures 9(a) and 9(b), where we have plotted the square of $\alpha E$ as a function of the photon energy E for our thin films, a bandgap of about $2.95 \mathrm{eV}$ can be estimated at low temperature, which shrinks down to $2.88 \mathrm{eV}$ when increasing temperature to $300 \mathrm{~K}$. These measurements give values consistent with some of the previous measurements on $\mathrm{Mg}_{3} \mathrm{~N}_{2}$ powder samples [11,15], represented by dots in Figure 9(c), as well as with our own measurements on commercial $\mathrm{Mg}_{3} \mathrm{~N}_{2}$ microparticles (triangles in Figure 9(c)). As for many other semiconductors, the measured temperature dependence of the bandgap can be fitted by the so-called Varshni formula [42]:

$$
E_{g}(T)=E_{0}-\delta T^{2} /(T+\beta)
$$

where $T$ is the temperature, $E_{0}$ is the bandgap energy at $0 \mathrm{~K}$ and $\delta$ and $\beta$ are constants to be extracted from the fit. Similarly, the temperature dependence of the energy bandgap can be also described by the more physically-meaningful model developed by K. O'Donnell et al. [43], which considers electronphonon coupling and takes into account the phonon density of states and their Bose-Einstein occupation probability:

$$
E_{g}(T)=E_{0}-2 \alpha_{B} \theta_{B}\left[\operatorname{coth}\left(\frac{\theta_{B}}{2 T}\right)-1\right]
$$

with $\alpha_{\mathrm{B}}$ and $k \theta_{\mathrm{B}}$ being the coupling constant and the average phonon energy, respectively. Table II gives the values for the three parameters defining each of the models for a typical $\mathrm{Mg}_{3} \mathrm{~N}_{2}$ film as well as for the commercial $\mathrm{Mg}_{3} \mathrm{~N}_{2}$ powder. 
Note first that the bandgap value at room temperature measured on our thin films as well as on the powder (both, ours and that used in reference [15]) coincide, indicating a $\mathrm{Mg}_{3} \mathrm{~N}_{2}$ bandgap at roomtemperature of about $2.90 \mathrm{eV}$. It is however surprising that the bandgap shrinkage between roomtemperature and $10 \mathrm{~K}$ is different: while the $70-100 \mathrm{meV}$ bandgap shrinkage in our thin films is comparable to that observed in standard semiconductors such as GaAs or GaN [44], the bandgap shrinkage measured on the $\mathrm{Mg}_{3} \mathrm{~N}_{2}$ powder is relatively large $(\sim 150 \mathrm{meV})$ compared to other semiconductors.

Indeed, if we assume that the absorption band edge we measure corresponds to transitions between the same two bands in the whole temperature range (note that band crossings cannot be totally excluded considering the theoretical calculations discussed in Section I), then its shift with temperature depends only on two terms. The first one is associated to the thermal expansion of the lattice and the second one is linked to the band energies renormalization due to electron-phonon interactions [30]. While in most cases the second term dominates [45], one might hypothesize that the relatively large thermal expansion coefficient of $\mathrm{Mg}_{3} \mathrm{~N}_{2}$ might result for the current material in a nonnegligible contribution of the thermal expansion to the shrinkage of the bandgap. However, if this were the sole reason explaining the strong bandgap shrinkage then we would have expected an even larger shrinkage for our $\mathrm{Mg}_{3} \mathrm{~N}_{2}$ thin films, which are epitaxially "attached" to a substrate with a slightly larger thermal expansion coefficient.

Overall, while the precise temperature evolution of the $\mathrm{Mg}_{3} \mathrm{~N}_{2}$ bandgap and, in general, the electronic band structure of $\mathrm{Mg}_{3} \mathrm{~N}_{2}$ requires further work, our study allows discriminating between previous measurements and enables to establish the $\mathrm{Mg}_{3} \mathrm{~N}_{2}$ bandgap to be in the blue-violet wavelength range.

\section{CONCLUSION}

$\mathrm{Mg}_{3} \mathrm{~N}_{2}$ thin films have been grown along the [111] direction on $\mathrm{MgO}(100)$ substrates and their epitaxial character assessed. Thanks to these high-quality films the linear thermal expansion coefficient of the material has been measured for the first time for temperatures above room-temperature 
$\left(\alpha_{T} \sim 1.20 \times 10^{-5} \mathrm{~K}^{-1}\right)$, and its optical bandgap has been determined to be about $2.95 \mathrm{eV}$ at low temperature and confronted to that of $\mathrm{Mg}_{3} \mathrm{~N}_{2}$ microparticles. Overall, this work paves the way to exploit a new nitride material in wide bandgap optoelectronic applications and adds to other nitrides recently introduced (e.g. AlSiN $[46,47])$.

\section{Acknowledgments}

We acknowledge support from ANR through the project ZONE (ANR-17-CE24-0043-01). 


\section{Figures Caption}

Figure 1: $2 \theta / \omega$ scans recorded at ambient conditions on commercial $\mathrm{Mg}_{3} \mathrm{~N}_{2}$ microparticles from Alfa Aesar $(99.5 \%)$ as a function of time. For air exposures shorter than $6 h$, peaks corresponding to diffraction from (222), (213), (004) and (233) $\mathrm{Mg}_{3} \mathrm{~N}_{2}$ planes are observed, while for longer exposures only a broad peak corresponding to $\mathrm{Mg}(\mathrm{OH})_{2}$ is recorded. Insets show photographs of (a) the initial powder and (b) the powder after $24 \mathrm{~h}$.

Figure 2: $\mathrm{MgO}(100)$ homoepitaxy. RMS roughness extracted from $2 \times 2 \mu m^{2}$ AFM images as a function of growth temperature and $\mathrm{O}_{2}$ flow. The inset shows the AFM image of an $\mathrm{MgO}(100)$ substrate after high-temperature annealing. (a)-(d) AFM images corresponding to the samples referenced by capital letters on the growth parameters diagram. The images size is the same and the scale is indicated in (d). The Z-scale in the four images corresponds to the maximum height.

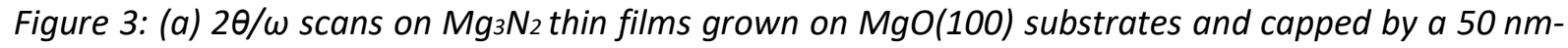
thick $\mathrm{MgO}$ layer. The letters $A$ to $\mathrm{F}$ refer to the different growth conditions reported in Table I. RHEED patterns of selected samples, where $(S)$ corresponds to the $\mathrm{MgO}$ substrate prior to the $\mathrm{Mg}_{3} \mathrm{~N}_{2}$ growth and $(A),(E)$ and $(F)$ correspond to the samples $A, E$ and $F$, respectively. (b) Growth rate of $M g_{3} N_{2}$ thin films as a function of $\mathrm{Mg}$ cell temperature for a constant $\mathrm{N}_{2}$ flow of $0.35 \mathrm{sccm}$. The detailed growth conditions for sample $G$ are reported in Table I as well.

Figure 4: XRR curve measured on sample $F$. The fit of the XRR curve has been performed using the GenX software.

Figure 5: (a) Large range 2 $\theta / \omega$ scan on a $\mathrm{Mg}_{3} \mathrm{~N}_{2}$ thin film (sample F) measured with a $1 / 4^{\circ}$ slit. (b) $2 \theta / \omega$ scan around the $\mathrm{Mg}_{3} \mathrm{~N}_{2}$ (222) reflection from the same sample in (a) performed with a crystal analyzer. The fit in (b) uses Equation (1).

Figure 6: XRD $\phi$-scans on (a) $M g_{3} \mathrm{~N}_{2}\{440\}$ planes and (b) $M g O\{220\}$ planes. (c) Schematic representation of the four $\mathrm{Mg}_{3} \mathrm{~N}_{2}$ rotational domains. (d) Schematic atomic model displaying the epitaxial relationship of one of the $\mathrm{Mg}_{3} \mathrm{~N}_{2}$ domains. The large dots correspond to the $\mathrm{Mg}$ atoms of the $\mathrm{MgO}$ substrate while the small dots correspond to the $\mathrm{N}$ atoms of the $\mathrm{Mg}_{3} \mathrm{~N}_{2}$ thin film. $\mathrm{O}$ atoms of the $\mathrm{MgO}$ substrate and $\mathrm{Mg}$ atoms of the $\mathrm{Mg}_{3} \mathrm{~N}_{2}$ layer were omitted for clarity. This leads for the $\mathrm{MgO}$ substrate to a square atomic lattice, given that $\mathrm{Mg}$ atoms from two consecutive (100) planes are represented.

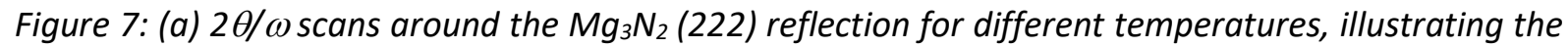
temperature-dependent lattice expansion. The dashed line is just a guide for the eyes. (b) Out-of-plane interplanar distances for the $\mathrm{Mg}_{3} \mathrm{~N}_{2}$ film and the $\mathrm{MgO}$ substrate as a function of temperature.

Figure 8: (a) Linear thermal expansion coefficient point by point for the MgO substrate, compared to previous published values (reference [35]). (b) Linear thermal expansion coefficient point by point for the $\mathrm{Mg}_{3} \mathrm{~N}_{2}$ film and previously published values at low temperatures (reference [36]). The linear thermal expansion coefficients have been calculated from Equation (2). Note that the horizontal (temperature) scales are not the same for (a) and (b).

Figure 9: Plot of $(a E)^{2}$ as a function of photon energy for $\mathrm{Mg}_{3} \mathrm{~N}_{2}$ thin films at (a) $12 \mathrm{~K}$ and (b) $300 \mathrm{~K}$. (c) Temperature dependence of the optical bandgap of $\mathrm{Mg}_{3} \mathrm{~N}_{2}$ thin films measured by transmission 
(squares), of $\mathrm{Mg}_{3} \mathrm{~N}_{2}$ powder measured by diffuse reflectance in this work (triangles), as well as previous values extracted from PLE spectra in reference [15]. The dashed lines in figure (c) correspond to the fit of the experimental data to O'Donnell's model (reference [43]). 


\section{Tables Caption}

Table I: Growth conditions of the series of $\mathrm{Mg}_{3} \mathrm{~N}_{2}$ thin films grown on $\mathrm{MgO}(100)$ substrates and capped with an MgO layer.

Table II: Fitting parameters of the Varshni phenomenological formula (first three rows) and O'Donnell's model (second three rows) for the temperature dependence of the bandgap. The fitting parameters have been determined for a typical $M g_{3} N_{2}$ epitaxial thin film and the commercial $M g_{3} N_{2}$ powder. 
Table I:

\begin{tabular}{cccccc}
\hline \hline Sample & $\begin{array}{c}\text { Growth temperature } \\
\left({ }^{\circ} \mathrm{C}\right)\end{array}$ & $\begin{array}{c}\text { Mg cell temperature } \\
\left({ }^{\circ} \mathrm{C}\right)\end{array}$ & $\begin{array}{c}\text { Nitrogen flow } \\
(\mathrm{sccm})\end{array}$ & $\begin{array}{c}\text { Thickness } \\
(\mathrm{nm})\end{array}$ & \begin{tabular}{c} 
Orientation \\
\hline \hline $\mathrm{A}$
\end{tabular} \\
\hline \hline $\mathrm{B}$ & 400 & 410 & 1 & 168 & $(100)+\mathrm{MgON}$ \\
$\mathrm{C}$ & 400 & 410 & 0.5 & 110 & $(100)$ \\
$\mathrm{D}$ & 400 & 410 & 0.35 & 73 & $(100)+(111)$ \\
$\mathrm{E}$ & 400 & 420 & 0.35 & 92 & $(100)+(111)$ \\
$\mathrm{F}$ & 400 & 430 & 0.35 & 98 & $(111)$ \\
$\mathrm{G}$ & 460 & 430 & 0.35 & 97 & $(111)$ \\
\hline \hline
\end{tabular}

Table II:

\begin{tabular}{ccc}
\hline \hline & Thin film & Powder \\
\hline \hline$E_{0}(\mathrm{eV})$ & 2.93 & 3.06 \\
$\delta(\mathrm{eV} / \mathrm{K})$ & $4.01 \cdot 10^{-3}$ & $4.03 \cdot 10^{-3}$ \\
$\beta(\mathrm{K})$ & 5187 & 1882 \\
\hline \hline $\mathrm{E}_{0}(\mathrm{eV})$ & 2.94 & 3.05 \\
$\alpha_{\mathrm{B}}(\mathrm{eV} / \mathrm{K})$ & $8.91 \cdot 10^{-5}$ & $2.92 \cdot 10^{-4}$ \\
$\mathrm{k} \theta_{\mathrm{B}}(\mathrm{meV})$ & 23 & 35 \\
\hline \hline
\end{tabular}




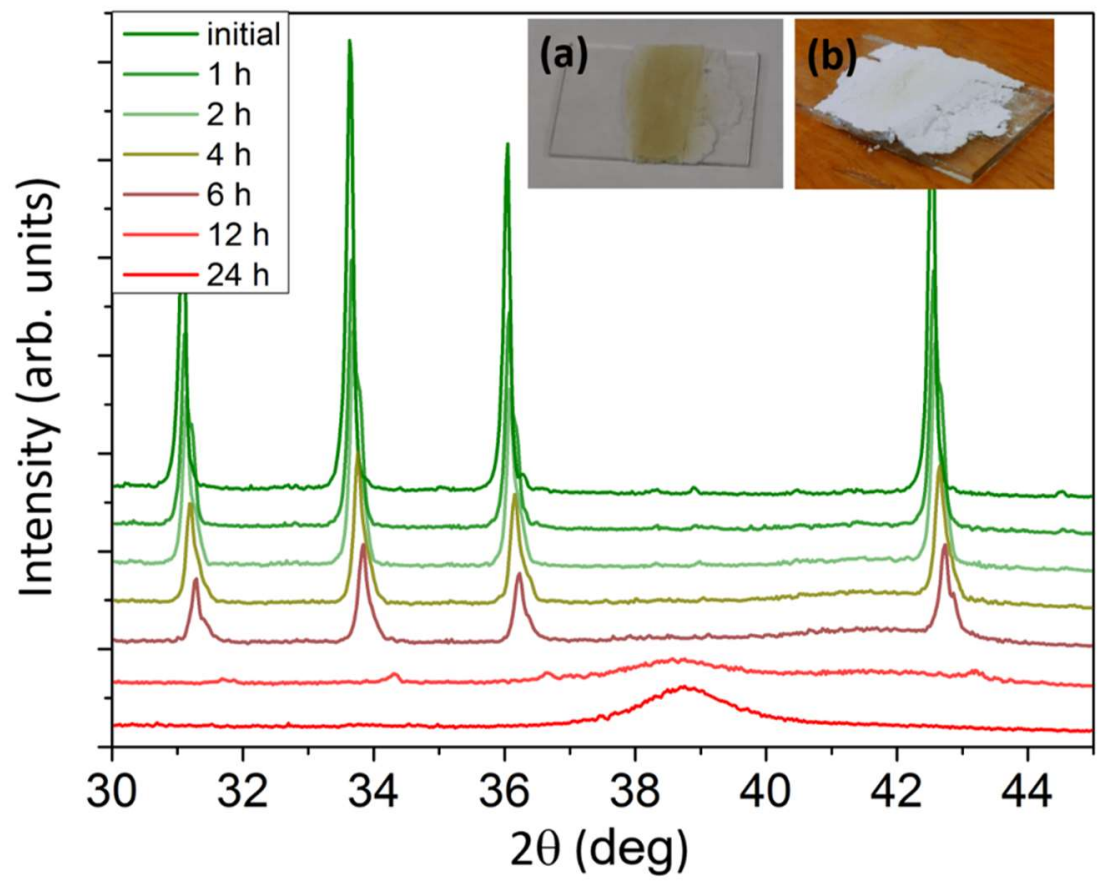

Figure 1 


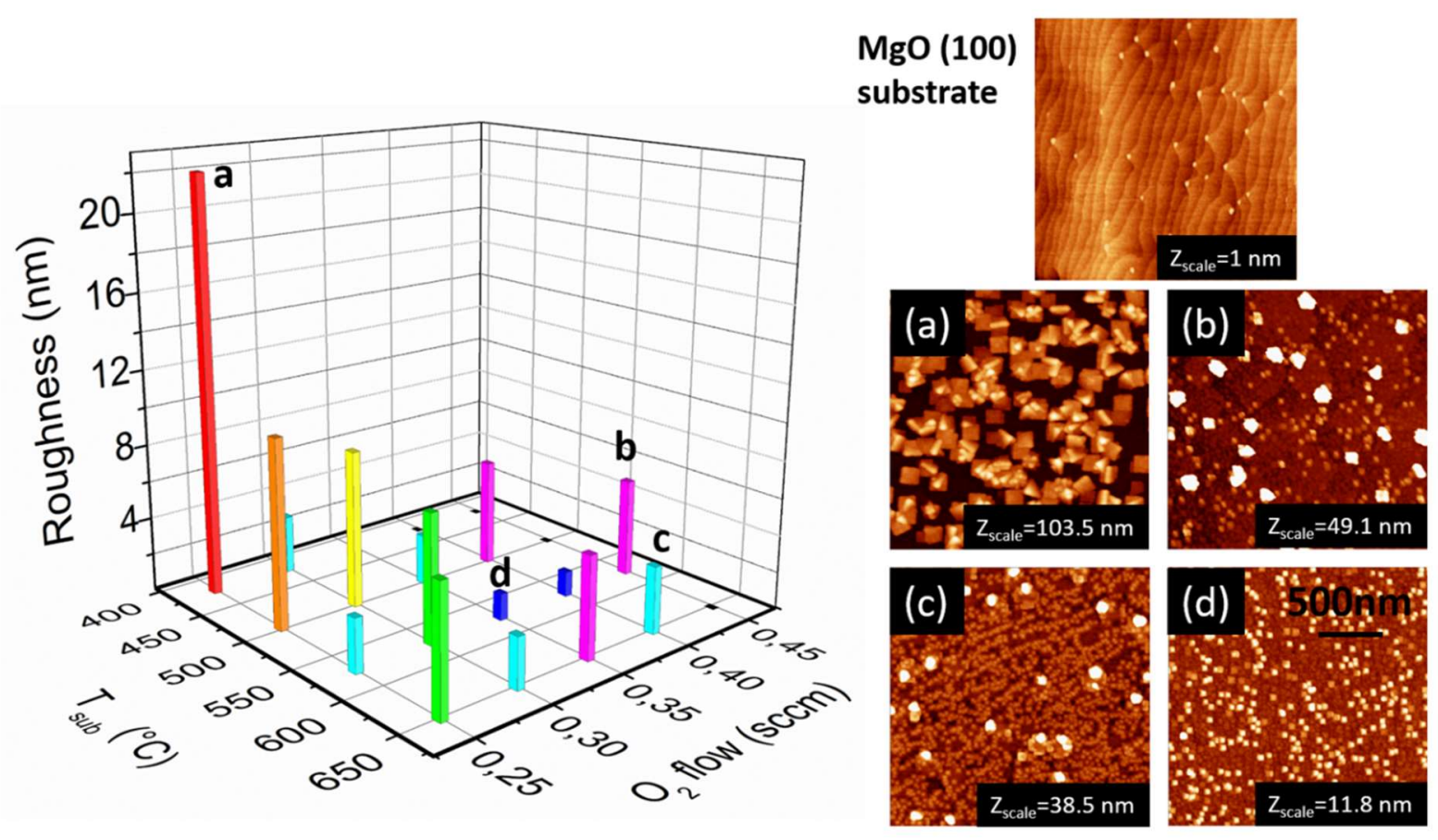

Figure 2 

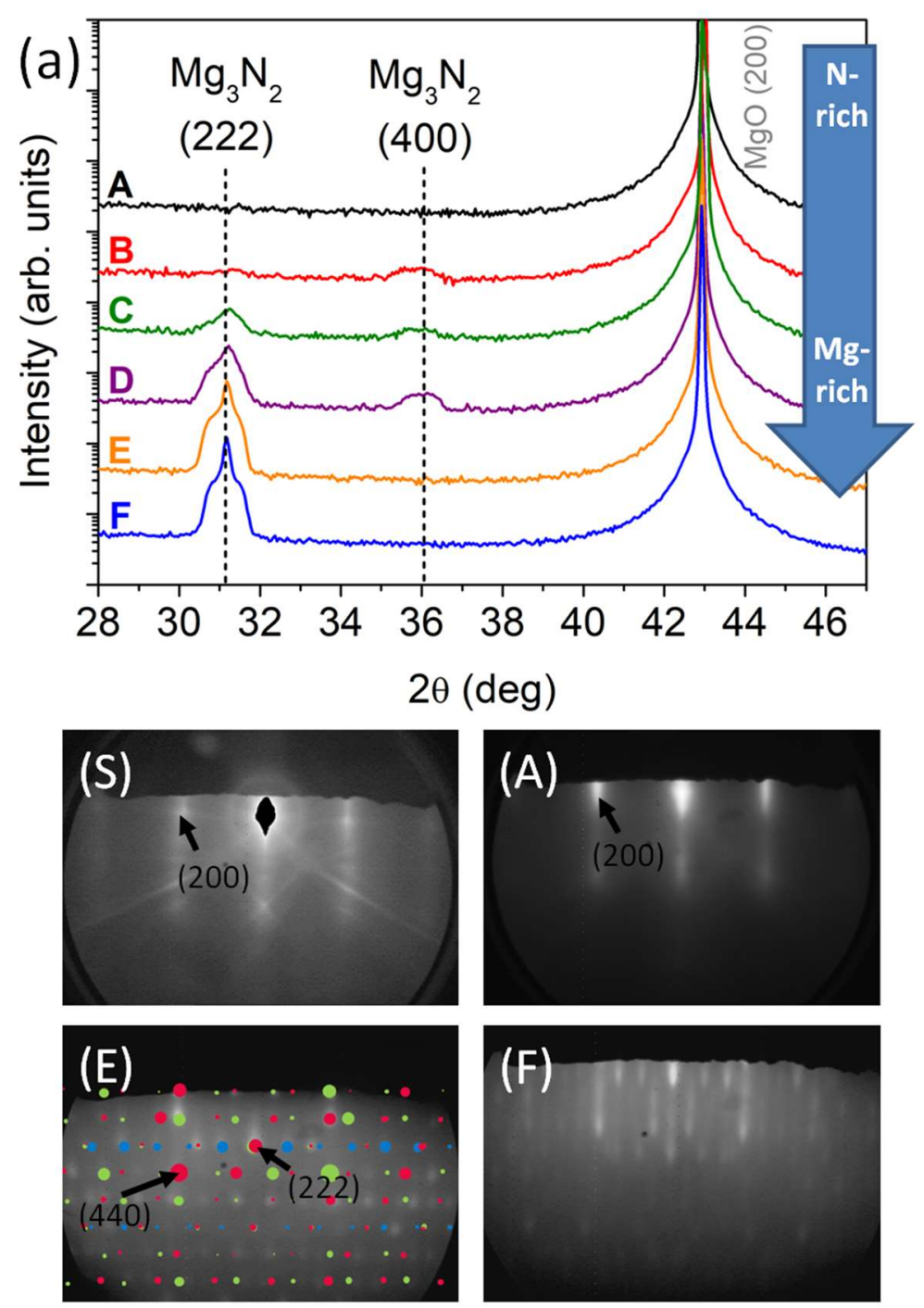

(b)

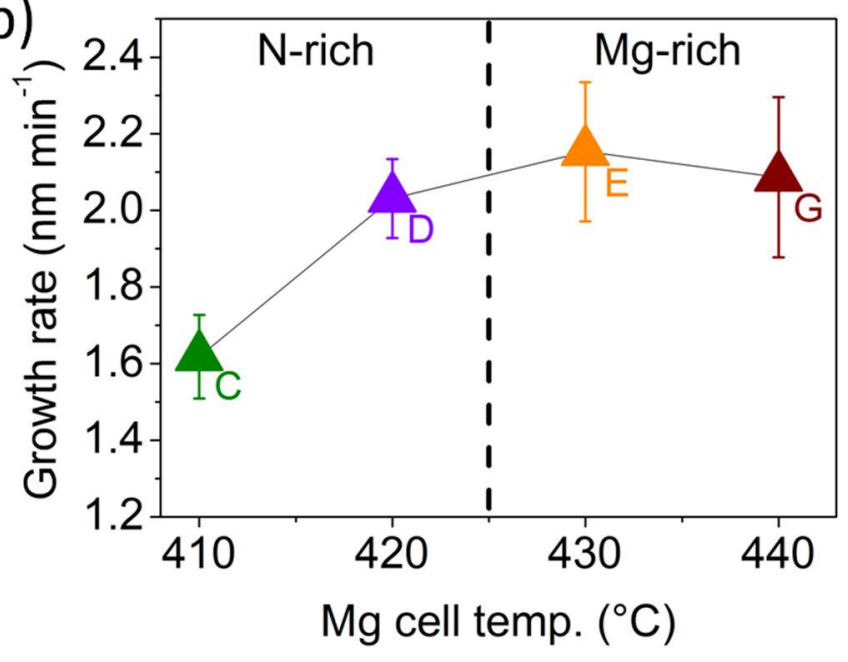

Figure 3 


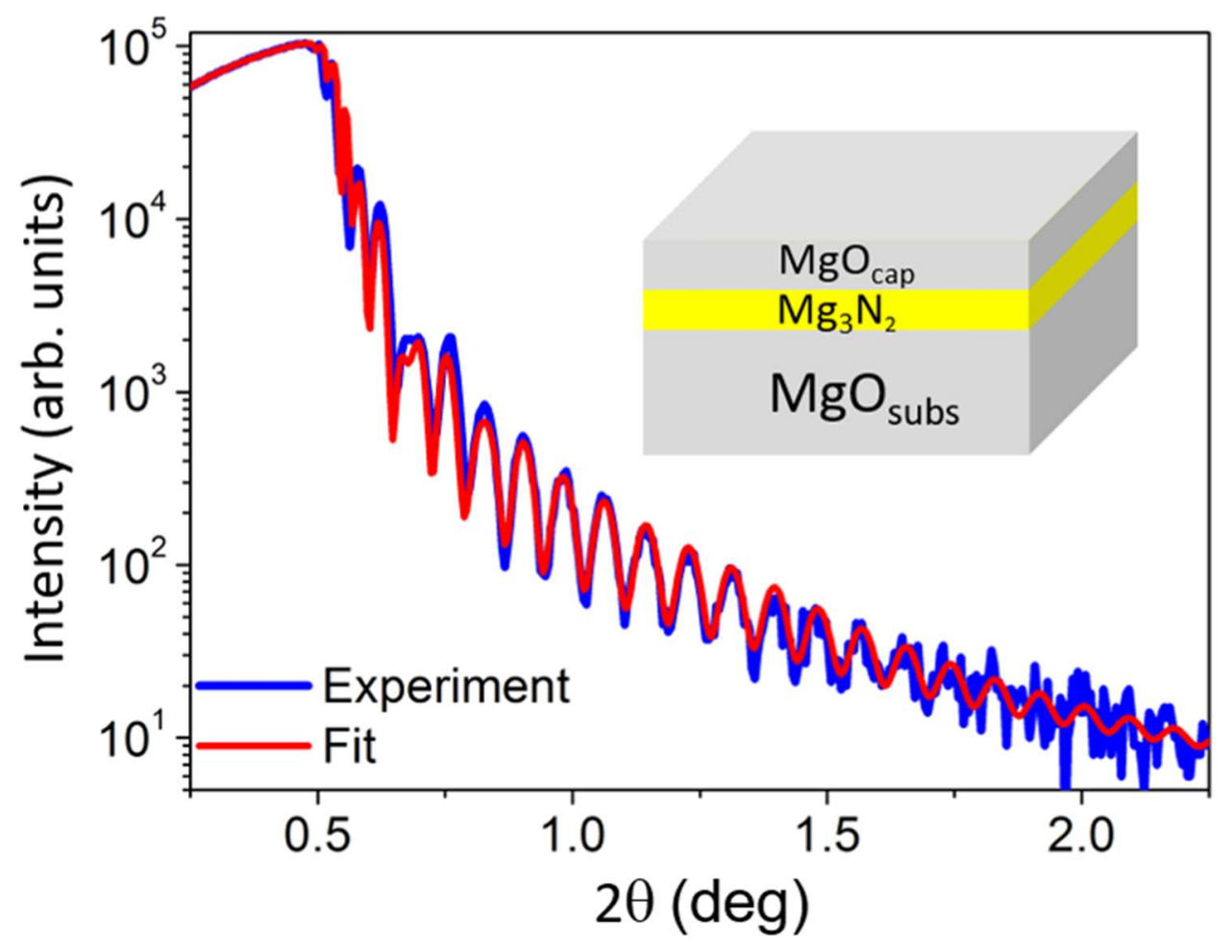

Figure 4 

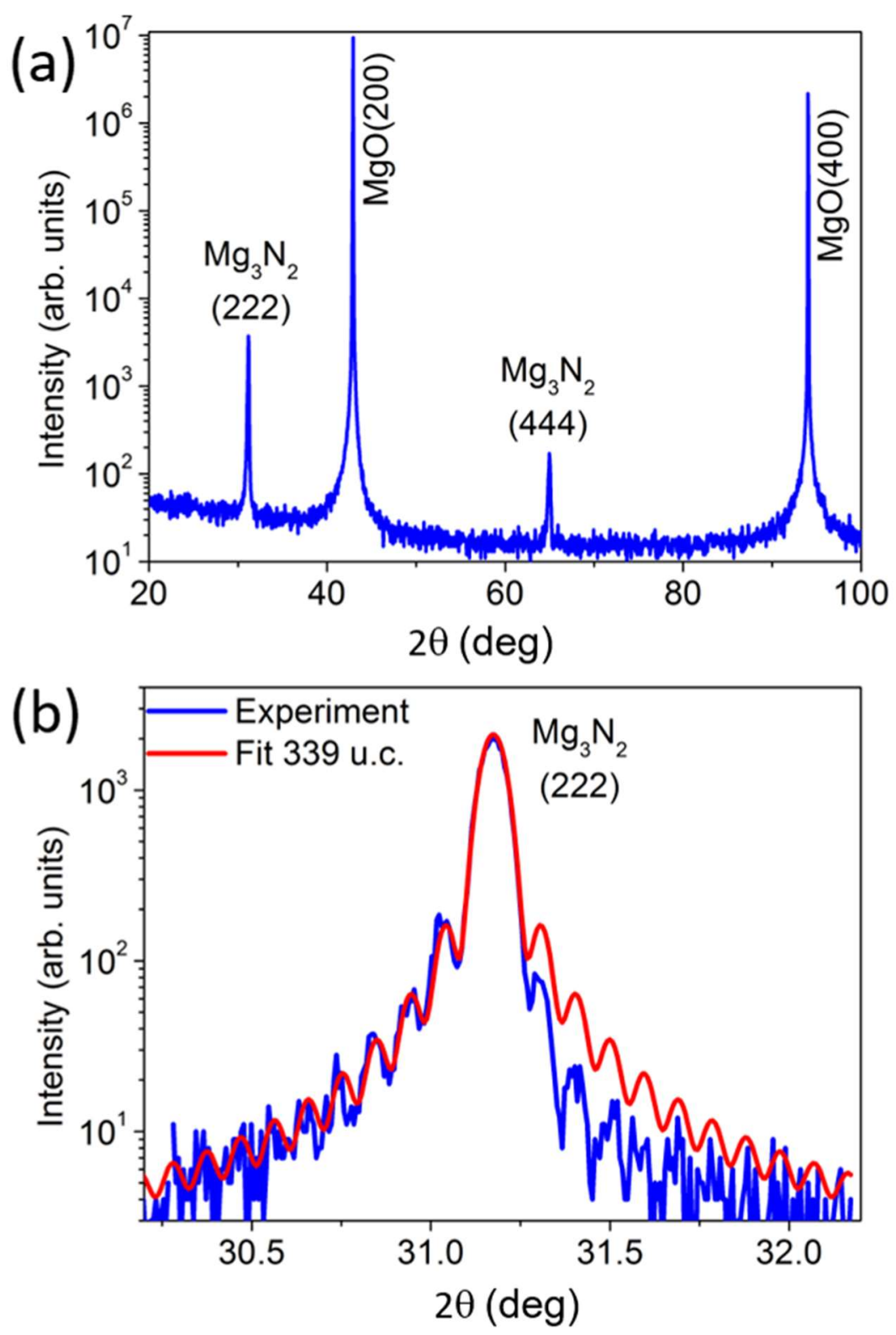

Figure 5 

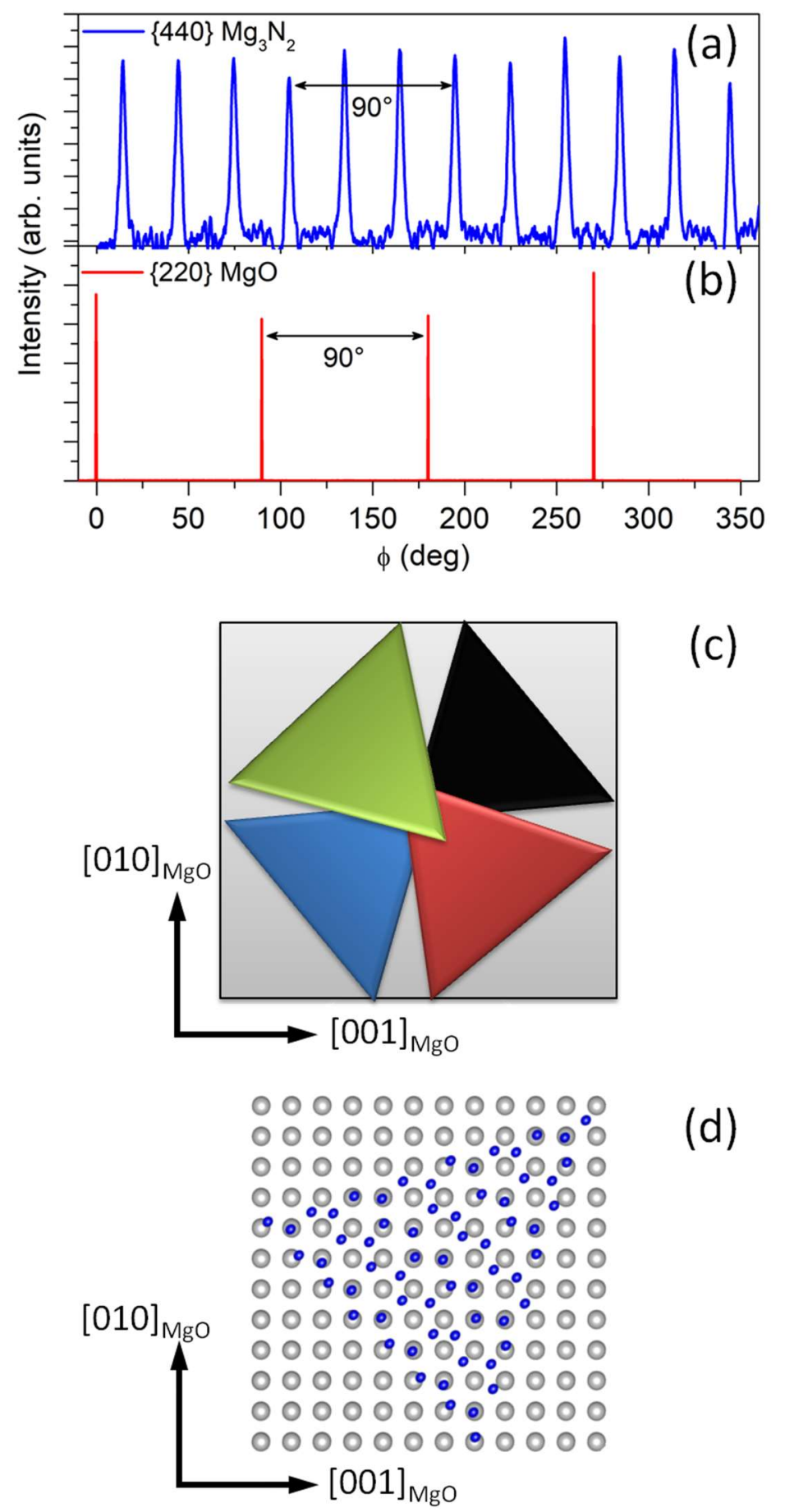

(c)

Figure 6 


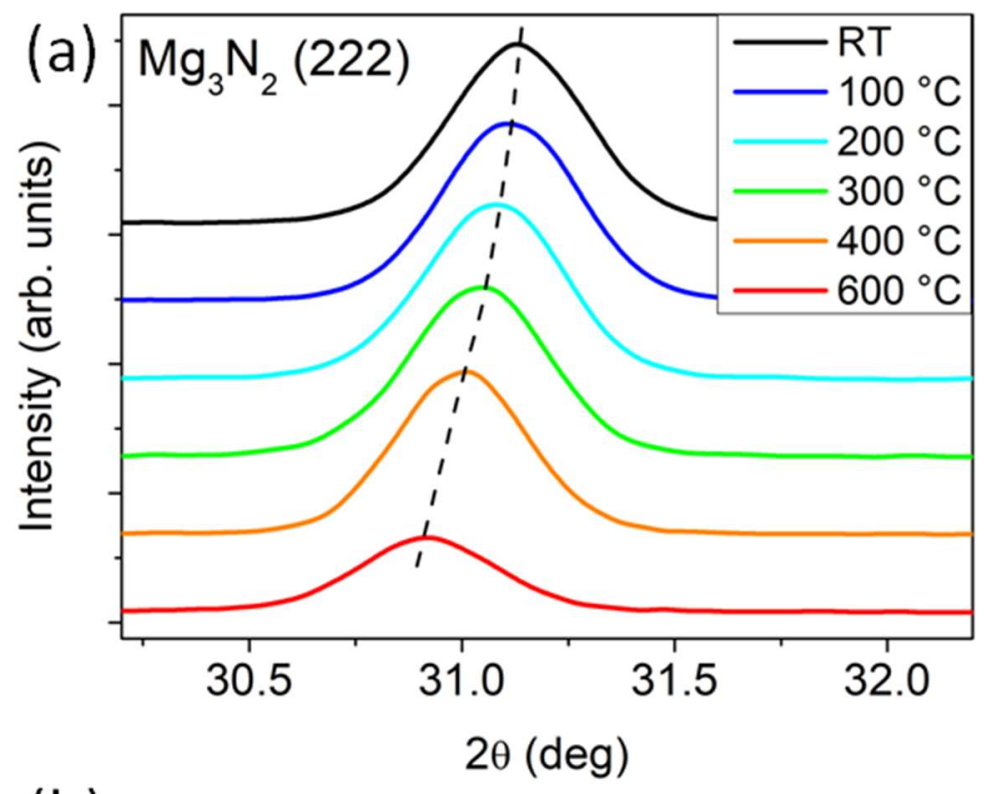

(b)

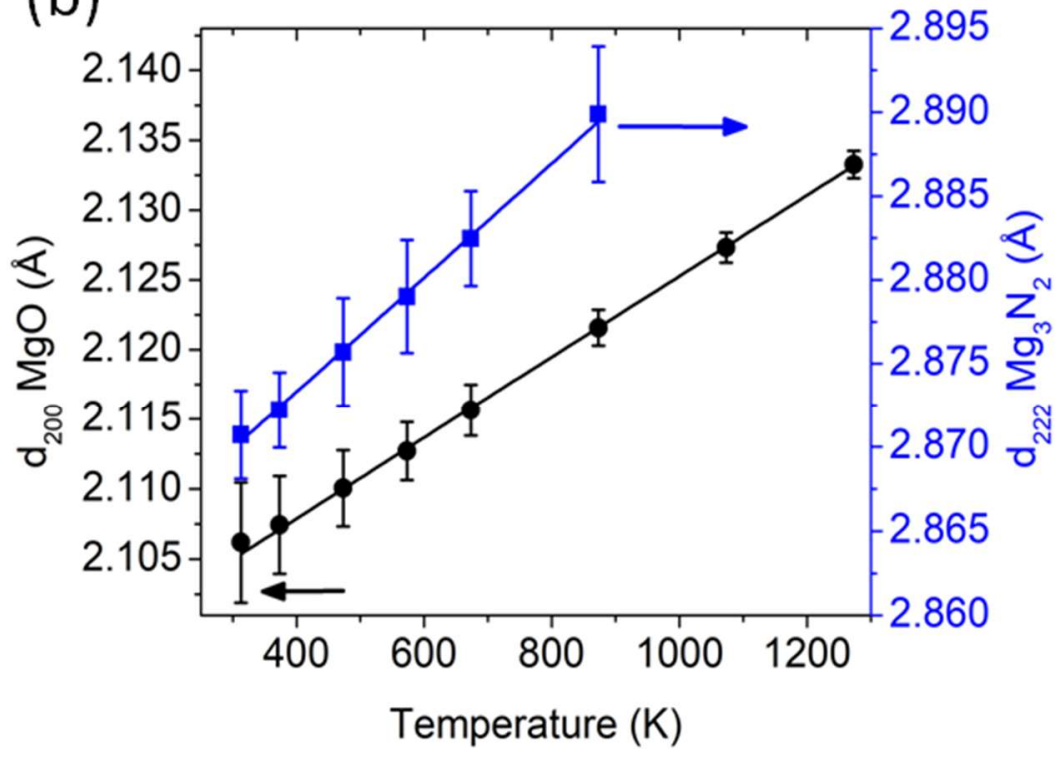

Figure 7 

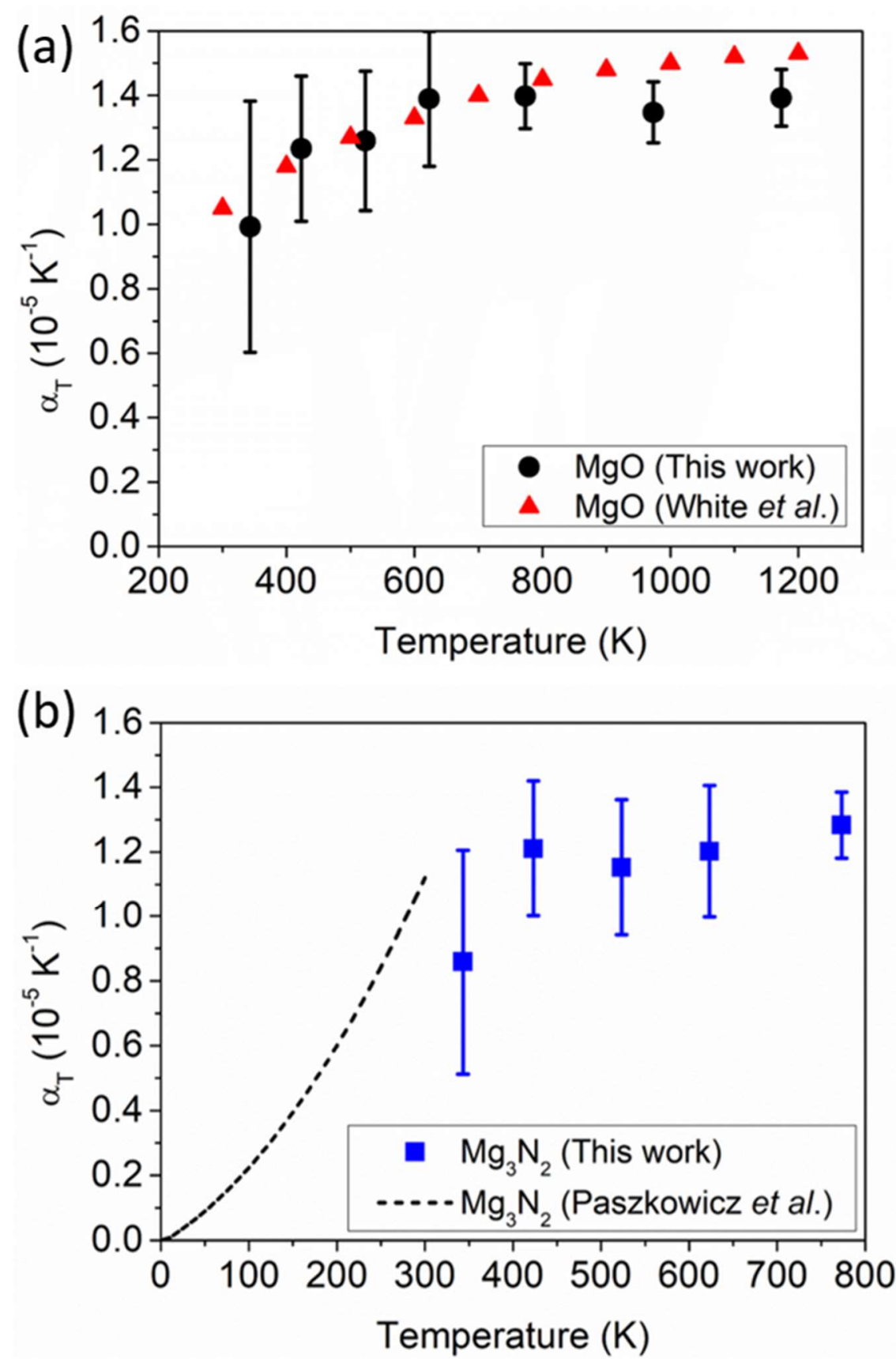

Figure 8 

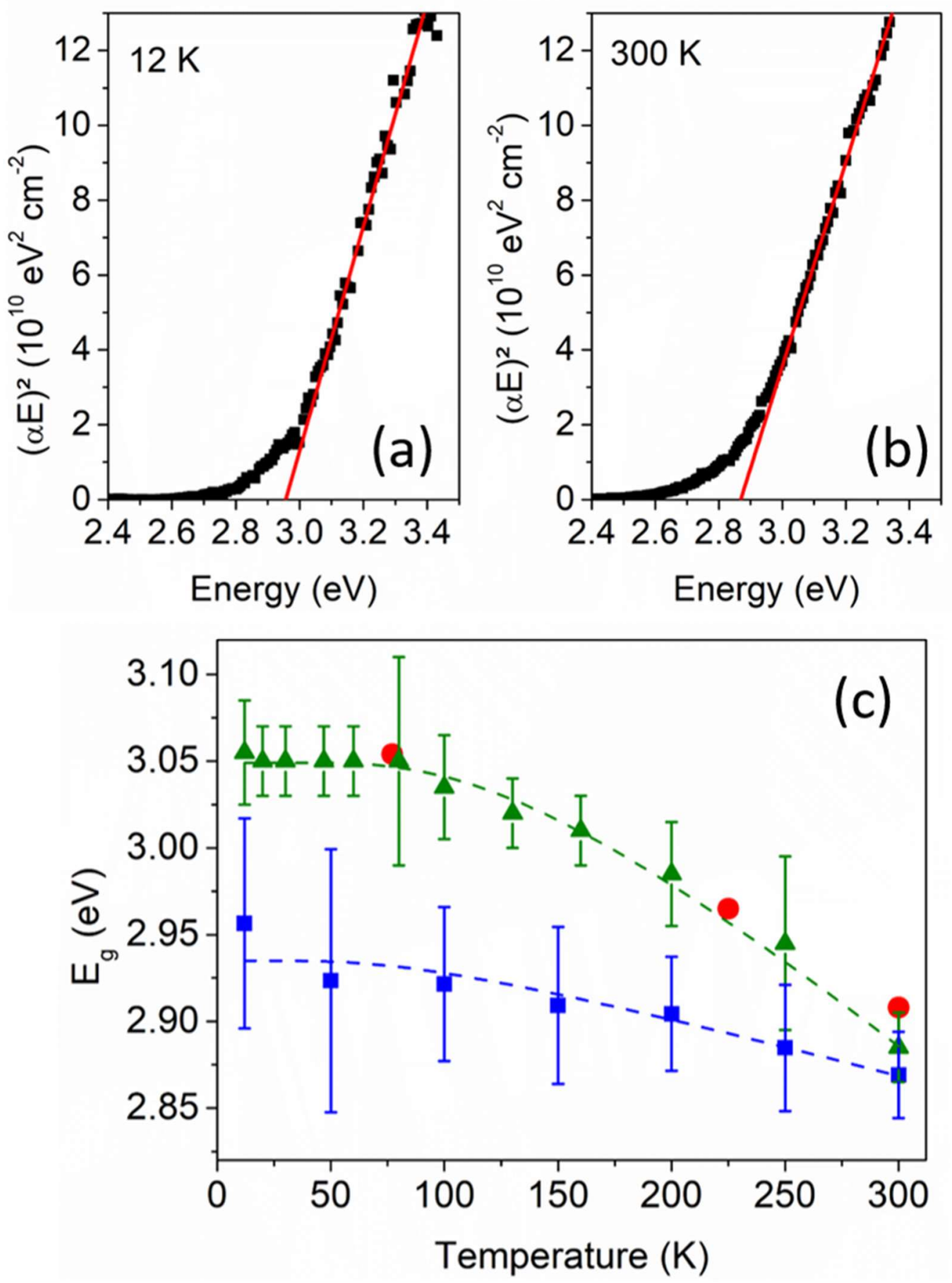

Figure 9 


\section{References}

[1] " Bandedge and optical functions of InN", M. Leroux and B. Gil, chapter A4.1 in "Gallium Nitride and Related Semiconductors", Datareviews series, No. 23 (1998).

[2] V. Yu. Davidov, A. A. Klochikhin, R. P. Seisyan, V. V. Emtsev, S. V. Ivanov, F. Bechstedt, J.

Furthmüller, H. Harima, A. V. Mudryi, J. Aderhold, O. Semchinova, and J. Graul, Phys. Status Solidi B 229, R1 (2002).

[3] V. Yu. Davidov, A. A. Klochikhin, V. V. Emtsev, S. V. Ivanov, V. V. Vekshin, F. Bechstedt, J.

Furthmüller, H. Harima, A. V. Mudryi, A. Hashimoto, A. Yamamoto, J. Aderhold, J. Graul and E. E. Haller, Phys. Status Solidi B 230, R4 (2002).)

[4] M. v. Stackelberg und R. Paulus, Z. Phys. Chem. B 22, 30 (1933)

[5] D. E. Partin, D. J. Williams, and M. O'Keeffe, J. Sol. Stat. Chem. 132, 56 (1997)

[6] I. Parkin and A. Nartowski, Polyhedron 17, 2617 (1998)

[7] H. Ye, X. Liu, and B. Luan, Mater. Lett. 58, 2361 (2004).

[8] G. Bocquillon, C. Loriers-Susse, and J. Loriers, J. Mater. Sci. 28, 3547 (1993).

[9] Z. Lences, K. Hirao, Y. Yamauchi, and S. Kanzaki, J. Am. Ceram. Soc. 86, 1088 (2003)

[10] U. Ash-Kurlander, G. E. Shter, S. Kababya, A. Schmidt, and G. S. Grader, J. Phys. Chem. C 117, 1237 (2013).

[11] C. M. fang, R. A. de Groot, R. J. Bruls, H. T. Hintzen, and G. de With, J. Phys.: Cond. Mat. 11, 4833 (1999).

[12] E. Orhan, S. Jobic, R. Brec, R. Marchand, and J. Y. Saillard, J. Mater. Chem. 12, 2475 (2002).

[13] M. G. Moreno Armenta, A. Reyes-Serrano, and M. Avalos Borja, Phys. Rev. B 62, 4890 (2000).

[14] P. Wu and T. Tiedje, Appl. Phys. Lett. 113, 082101 (2018).

[15] Y. Uenaka and T. Uchino, J. Phys. Chem. C 118, 11895 (2014).

[16] K. Toyoura, T. Goto, K. Hachiya, and R. Hagiwara, Electrochem. Acta 51, 56 (2005).

[17] P. Wu, X. Cao, T. Tiedje and N. Yamada, Mater. Lett. 236, 649 (2019).

[18] P. Vennéguès, M. Benaissa, B. Beaumont, E. Feltin, P. de Mierry, S. Dalmasso, M. Leroux, and P. Gibart, Appl. Phys. Lett. 77, 880 (2000).

[19] M. Hansen, L. F. Chen, S. H. Lim, S. P. DenBaars, and J. S. Speck, Appl. Phys. Lett. 80, 2469 (2002).

[20] P. Vennéguès, M. Leroux, S. Dalmasso, M. Benaissa, P. De Mierry, P. Lorenzini, B. Damilano, B.

Beaumont, J. Massies, and P. Gibart, Phys. Rev. B 68, 235214 (2003).

[21] D. R. Glasson and S. A. A. Jayaweera, J. Appl. Chem. 18, 77 (1968).

[22] X. D. Peng, D. S. Edwards, and M. A. Barteau, Surf. Sci. 195, 103 (1988).

[23] A. M. Heyns, L. C. Prinsloo, K. J. Range, and M. Stassen, J. Sol. Stat. Chem. 137, 33 (1998)

[24] K. J. Chang and M. L. Cohen, Phys. Rev. B 30, 4774 (1984).

[25] M. Björck and G. Anderson, J. Appl. Cryst. 40, 1174 (2007).

[26] J. Triscone, P. Fivat, M. Andersson, M. Decroux, and O. Fischer, Phys. Rev. B 50, 1229 (1994).

[27] J. Bläsing, A. Krost, J. Hertkorn, F. Scholz, L. Kirste, A. Chuvilin, and U. Kaiser, J. Appl. Phys. 105, 033504 (2009).

[28] M. Grundmann, T. Böntgen, and M. Lorenz, Phys. Rev. Lett. 105, 146102 (2010).

[29] M. Grundmann, Phys. Stat. Sol. B 248, 805 (2011).

[30] P. Lautenschlager, P. B. Allen, and M. Cardona, Phys. Rev. B 31, 2163 (1985).

[31] G. A. Slack, and S. F. Bertram, J. Appl. Phys. 46, 89 (1975).

[32] F. Liu and B. Zheng, Powder Diffr. 6, 147 (1991).

[33] F. Liu, Powder Diffr. 8, 36 (1993).

[34] R. J. Beals, and R. L. Cook, J. Am. Ceram. Soc. 40, 279 (1957).

[35] G. K. White and O. L. Anderson, J. Appl. Phys. 37, 430 (1966).

[36] W. Paszkowicz, M. Knapp, J. Z. Domagala, G. Kamler, and S. Podsiadlo, J. All. Comp. 328, 2372

(2001)

[37] H. Ibach, phys. stat. sol. 31, 625 (1969)

[38] H. Ibach, phys. stat. sol. 33, 257 (1969) 
[39] H. Köncke, S. Figge, B. M. Epelbaum, and D. Hommel, Act. Phys. Pol. A 114, 1193 (2008)

[40] F. Datchi, A. Dewaele, Y. Le Godec, and P. Loubeyre, Phys. Rev. B 75, 214104 (2007).

[41] M. Leszczynski, T. Suski, H. Teyssiere, P. Perlin, I. Grzegory, J. Jun, S. Porowski, and T. D. Moustakas, J. Appl. Phys. 76, 4909 (1994).

[42] Y. Varhsni, Physica 34, 149 (1967)

[43] K. P. O'Donnell and X. Chen, Appl. Phys. Lett. 58, 2924 (1991)

[44] I. Vurgaftman, J. R. Meyer, and L. R. Ram-Mohan, J. Appl. Phys. 89, 5815 (2001).

[45] S. Biernacki, U. Scherz, and B. K. Meyer, Phys. Rev. B 49, 4501 (1994).

[46] R. Dagher, L. Lymperakis, V. Delaye, L. Largeau, A. Michon, J. Brault, and P. Vennéguès, Sci. Rep. 9, 15907 (2019)

[47] F. Semond, E. Frayssinet and J. Massies, US2018/0012753 